\title{
Yielding stability and usefulness of spring barley varieties to compose mixtures
}

\section{Stabilność plonowania mieszanek i przydatność odmian jęczmienia jarego do komponowania zasiewów mieszanych}

\author{
Anna Tratwal ${ }^{1}$, Jadwiga Nadziak ${ }^{2}$
}

\section{Summary}

In recent years around $17 \%$ of all cereal crop area is cultivated with variety and species mixtures. Modern plant protection methods need to be compliant with concept of integrated production and control whose premise needs to be economically profitable, environmentally-friendly and socially accepted. Field experiments with spring barley varieties were carried out at two localities in 2010-2013. Based on the obtained results usefulness of five spring barley varieties to compose two- and three-way mixtures, yielding and yield stability were evaluated. To assess the suitability of varieties in mixtures comparative analysis of actual and expected yields in two- and three-way mixtures were performed.

Key words: spring barley; mixtures; stability; yielding

\section{Streszczenie}

W ostatnich latach około $17 \%$ ogólnego areału upraw zbożowych zajmowały mieszanki, zarówno międzygatunkowe, jak i międzyodmianowe. Systemy ochrony roślin muszą być zgodne z ideą rolnictwa integrowanego, którego założeniem jest ochrona roślin korzystna ekonomicznie, przyjazna środowisku, jak i akceptowana społecznie. Na podstawie wyników z doświadczenia ścisłego z odmianami jęczmienia jarego, które przeprowadzono w latach 2010-2013 w dwóch miejscowościach, oszacowano przydatność pięciu odmian jęczmienia jarego do komponowania mieszanek dwu- i trzyskładnikowych. Odmiany jęczmienia jarego wysiano w siewie czystym oraz we wszystkich możliwych mieszankach dwu- i trzyskładnikowych. W pracy oceniano plonowanie, stabilność plonowania oraz przydatność odmian do uprawy w zasiewach mieszanych. Do oszacowania przydatności odmian w zasiewach mieszanych zastosowano analizę porównawczą plonów rzeczywistych i oczekiwanych w mieszankach dwuskładnikowych i trzyskładnikowych.

Key words: jęczmień jary; mieszanki; stabilność; plonowanie

\footnotetext{
Instytut Ochrony Roślin - Państwowy Instytut Badawczy

Władysława Węgorka 20, 60-318 Poznań

${ }^{2}$ Hodowla Roślin Smolice Sp. z o.o. - Grupa IHAR

Oddział Bąków

Braci Bassy 32, 46-233 Bąków

*corresponding author: a.tratwal@iorpib.poznan.pl
} 


\section{Wstęp / Introduction}

Praktyczne stosowanie integrowanej ochrony roślin wiąże się z wykorzystaniem, na ile to możliwe, wszelkich alternatywnych dla ochrony chemicznej metod zwalczania agrofagów. Głównym zadaniem i celem nowoczesnych systemów ochrony roślin jest to, że muszą być one zgodne $\mathrm{z}$ ideą rolnictwa zrównoważonego, które z założenia powinno być korzystne ekonomicznie, przyjazne środowisku, jak i akceptowane społecznie oraz zgodne z ideą dobrej praktyki ochrony roślin (Finckh i wsp. 2000; Gacek 2000).

Jednym z tańszych i stosunkowo łatwym sposobem różnicowania i jednocześnie zwiększania trwałości odporności genetycznej współczesnych odmian w warunkach produkcyjnych jest ich uprawa w rozmaitych typach zasiewów mieszanych. Pod pojęciem „zasiewy mieszane” rozumiemy zarówno międzygatunkowe mieszanki (zbożowo-strączkowe i zbożowo-zbożowe), jak i mieszanki międzyodmianowe w obrębie jednego gatunku. Najważniejszą zaletą uprawy zbóż w mieszankach jest wprowadzenie bioróżnorodności, która dzięki odrębności wprowadzanych roślin pozwala na lepsze wykorzystanie zasobów środowiska, bez zakłócania jego równowagi biologicznej (Wolfe 1990; Finckh i wsp. 2000; Gacek 2000; Nadziak i Tratwal 2012).

Doświadczalnie, a także w warunkach produkcyjnych dowiedziono, nawet $40-50 \%$ redukcję porażenia przez choroby $\mathrm{w}$ dobrze skomponowanych mieszankach odmianowych w porównaniu do średniego porażenia ich komponentów w siewach czystych, w siewach międzygatunkowych redukcje te są jeszcze większe, rzędu 50-60\%. Uprawa zasiewów mieszanych prowadzi do obniżenia kosztów i ochrony środowiska oraz zmniejsza zużycie fungicydów i insektycydów dzięki ograniczeniu do minimum liczby zabiegów opryskiwania (Wolfe 1990; Gacek i wsp. 1996; Wolfe i wsp. 1997; Finckh i wsp. 2000; Noworolnik 2000; Michalski i wsp. 2004; Tratwal i wsp. 2007a, b; Tratwal i Walczak 2010; Szempliński i Budzyński 2011).

Wiele doświadczeń i doniesień naukowych zwraca uwagę na wyższe i stabilniejsze plonowanie mieszanek w porównaniu do odmian wysianych w siewie czystym. Wobec powyższych korzyści wynikających z uprawy mieszanek odmianowych ważnym zagadnieniem w zasiewach mieszanych jest poznanie wzajemnego oddziaływania roślin na siebie w celu określenia doboru odmian. Plonowanie odmian $\mathrm{w}$ siewie mieszanym związane jest $\mathrm{z}$ efektem komplementacji, kompensacji i konkurencyjności roślin. Efekt komplementacji związany jest $\mathrm{z}$ korzystnym oddziaływaniem roślin różnych odmian na siebie podczas wegetacji. Natomiast efekt kompensacji polega na różnym wykorzystaniu przestrzeni przez poszczególne komponenty siewu mieszanego. Ważne jest również zjawisko konkurencyjności między roślinami, które polega na zróżnicowaniu roślin w poszczególnych fazach rozwojowych. Konkurencyjność między roślinami różnych odmian prowadzi do lepszego wykorzystania przestrzeni otaczającej rośliny.

Do opisu wzajemnego oddziaływania roślin na siebie Allard i Adams (1969) wprowadzili określenie ,ekologiczna zdolność kombinacyjna odmian” (ecological combining ability). Odmiany, które mają wysoką „ekologiczną zdolność kombinacyjną" i dobre uzdolnienia konkurencyjne plonują wyżej w sąsiedztwie roślin innych odmian niż w sąsiedztwie własnych roślin. Mieszanki mogą plonować wyżej od najplenniejszego komponentu w siewie czystym wchodzącego w ich skład lub nawet plonować gorzej od najniżej plonującego komponentu. W pierwszym przypadku określane jest to jako dodatnie plony transgresywne, a w drugim jako ujemne plony transgresywne (Trenbath 1974; Gacek i wsp. 1997). Dotychczas podjęto wiele prób opracowania metod szacowania przydatności odmian do uprawy w siewie mieszanym (Trenbath 1974; Knott i Mundt 1990; Gacek i wsp. 1997; Nadziak i Tratwal 2012).

Celem pracy było oszacowanie wysokości i stabilności plonowania oraz przydatności odmian jęczmienia jarego do zasiewów mieszanych.

\section{Materiały i metody / Materials and methods}

Doświadczenie $\mathrm{z}$ odmianami w siewie czystym i mieszankami jęczmienia jarego wysiano w latach 2010-2013 w dwóch miejscowościach: „Hodowla Roślin Smolice Sp. z o.o. - Grupa IHAR" Oddział Bąków (województwo opolskie) na poletkach o powierzchni $10 \mathrm{~m}^{2}$ i Zakład Doświadczalny Oceny Odmian Kościelna Wieś (województwo wielkopolskie) na poletkach o powierzchni $15 \mathrm{~m}^{2}$ w czterech powtórzeniach.

W Bąkowie doświadczenie założono w roku:

- 2010 na glebie bielicowej, klasa IVa, przedplonem były buraki cukrowe,

- 2011 na glebie brunatnej wyługowanej, klasa V, przedplonem była kukurydza uprawiana na ziarno,

- 2012 na glebie bielicowej, klasa IVa, przedplonem były buraki cukrowe,

- 2013 na glebie bielicowej, klasa IIIb, przedplonem była kukurydza uprawiana na ziarno.

W doświadczeniu stosowano następujące nawożenie: $\mathrm{N}$ : 54-69 kg/ha, P: 60-69 kg/ha, K: 75-90 kg/ha.

W Kościelnej Wsi doświadczenie założono w roku:

- 2010 na glebie brunatnej wyługowanej lub kwaśnej, glina średnia pylasta, klasa IIIa, przedplonem była kukurydza na ziarno,

- 2011 na glebie brunatnej wyługowanej lub kwaśnej, glina średnia pylasta, klasa IIIb, przedplonem była kukurydza na ziarno,

- 2012 na glebie brunatnej wyługowanej lub kwaśnej, glina średnia pylasta, klasa IIIa, przedplonem była kukurydza na ziarno,

- 2013 na glebie brunatnej wyługowanej lub kwaśnej, glina średnia pylasta, klasa IIIa, przedplonem były buraki cukrowe.

W doświadczeniu stosowano następujące nawożenie: $\mathrm{N}$ : 60-70 kg/ha, P: 30-40 kg/ha, K: 50-60 kg/ha.

Materiałem doświadczalnym było pięć odmian jęczmienia jarego: Antek, Basza, Blask, Rubinek, Skarb oraz wszystkie kombinacje mieszanek dwu- i trzyskładnikowych. Z pięciu odmian można skomponować 10 mieszanek dwuskładnikowych i 10 mieszanek trzyskładnikowych. Normę wysiewu stanowiło 360 ziaren $/ \mathrm{m}^{2}$, a udział 
komponentów mieszanek wynosił 1:1 lub 1:1:1 w przypadku mieszanek trzyskładnikowych. Siewy wykonywano W terminach: 09.04.2010, 01.04.2011, 10.04.2012, 22.04.2013 (Bąków) i 08.04.2010, 31.03.2011, 04.04.2012, 18.04.2013 (Kościelna Wieś) przy wykorzystaniu siewnika poletkowego Oyord (Bąków) i SPZ 1,5/2 (Kościelna Wieś), w rozstawie rzędów 12,5 cm i głębokości siewu $3 \mathrm{~cm}$. Głównym kryterium doboru odmian było ich zróżnicowanie pod kątem odporności na najważniejsze choroby, np. mączniaka prawdziwego. Odmianą o największej podatności był Antek, odmianami najbardziej odpornymi były: Basza i Rubinek ze źródłem odporności Mlo.

Założeniem doświadczenia było niestosowanie ochrony fungicydowej i insektycydowej. W latach badań stosowano jednokrotny zabieg herbicydowy w fazie 2-3 liści (Bąków) i krzewienia (Kościelna Wieś) preparatem Mustang Forte $195 \mathrm{SE} w$ dawce $0,8 \mathrm{l} / \mathrm{ha}$.

Wpływ zasiewów mieszanych na plon ziarna określono porównując plony rzeczywiste (r) poszczególnych mieszanek $\mathrm{z}$ ich plonami oczekiwanymi (o). Plonem rzeczywistym był plon ziarna uzyskany z poletka, natomiast plonem oczekiwanym dla każdej mieszanki była średnia arytmetyczna z plonów ziarna komponentów mieszaniny w siewie czystym. Przydatność odmian do uprawy w siewie mieszanym określono na podstawie sumy różnic między plonami danej odmiany w siewie czystym a w zasiewach mieszanych.

Stabilność plonowania oceniono za pomocą współczynnika zmienności po stwierdzeniu istotności interakcji genotypowo-środowiskowej.

Współczynnik zmienności obliczono zgodnie ze wzorem podanym przez Węgrzyna (1989):

$$
\mathrm{v}_{1}=\frac{\left[1 /\left(\mathrm{n}-1 \sum \mathrm{z}_{\mathrm{ij}}-\mathrm{z}_{\mathrm{j}}\right)^{2}\right]^{0,5}}{\mathrm{z}_{\mathrm{i}}} \times 100
$$

$\mathrm{z}_{\mathrm{ij}}=\mathrm{x}_{\mathrm{ij}}-\mathrm{x}_{\mathrm{j}}+\mathrm{x} \ldots \quad \mathrm{z}_{\mathrm{i} .}=\sum \mathrm{x}_{\mathrm{ij}} / \mathrm{n}$

$\mathrm{z}_{\mathrm{ij}}-\quad$ poprawiony plon po wyeliminowaniu efektu środowiskowego, efekt środowiskowy obliczony jako różnica między średnią $\mathrm{j}$-tego środowiska $\left(\mathrm{x}_{\mathrm{ij}}\right)$ a średnią ogólną $\mathrm{x}$,

$\mathrm{z}_{\mathrm{i} .}-\quad$ wartości ${ }_{\mathrm{i}}$-tego genotypu dla środowisk.

\section{Wyniki i dyskusja / Results and discussion}

W latach badań spośród chorób obserwowanych na jęczmieniu jarym w większym nasileniu notowano mączniaka prawdziwego zbóż (Blumeria graminis f. sp. hordei). Inne choroby, jak rdzę karłową (Puccinia hordei) czy rynchosporiozę (Rhynchosporium secalis) obserwowano jedynie w niewielkim nasileniu, nie stanowiącym znaczenia gospodarczego. We wszystkich latach badań, średnio, odmiany w siewach czystych były bardziej porażone przez sprawcę mączniaka prawdziwego niż mieszanki.

W latach badań na odmianach jęczmienia jarego dominującymi szkodnikami były: mszyca czeremchowo-zbożowa (Rhopalosiphum padi L.), skrzypionki (Oulema spp.) na liściach oraz mszyca zbożowa (Sitobion avenae F.) na kłosach. W małej liczebności stwierdzano takie szkodniki, jak: miniarki (Agromyzidae), wciornastki (Thripidae), lednicę zbożową (Aelia acuminata L.), żółwinka zbożowego (Eurygaster maura L.). Sporadycznie stwierdzano: skoczki (Cicadellidae), niezmiarkę paskowaną (Chlorops pumilionis Bjerk.) oraz zwójki (Cnephasia sp.). Odnotowywano zwykle redukcję liczebności skrzypionek i mszyc w miejscowościach, w mieszankach w porównaniu do siewów czystych.

Na podstawie analizy wariancji przedstawionej w tabeli 1., stwierdzono istotną interakcję odmian jęczmienia jarego z lokalizacjami i oceniono stabilność plonowania oraz przydatność odmian do uprawy w zasiewach mieszanych czyli mixing ability.

W tabeli 2. przedstawiono średnie plony oraz współczynniki zmienności dla odmian w siewie czystym i mieszanek odmianowych.

W doświadczeniu najwyższym plonowaniem w siewie czystym wykazała się odmiana jęczmienia jarego Skarb $(56,73 \mathrm{dt} / \mathrm{ha})$, natomiast najbardziej stabilną, czyli o najniższym współczynniku zmienności CV (coefficient of variation) była odmiana Rubinek (5,94\%) (tab. 2). Dla odmian w siewie czystym współczynnik zmienności CV wynosił od 5,94\% dla odmiany Rubinek do 10,50\% dla odmiany Antek. Mieszanki odmian jęczmienia jarego plonowały bardziej stabilnie niż odmiany w siewie czystym. Spośród mieszanek dwuskładnikowych najwyższym potencjałem plonowania charakteryzowały się mieszanki o następującym składzie: Basza + Rubinek, Blask + Skarb, Blask + Rubinek. Wymienione mieszanki plonowały istotnie wyżej, na poziomie istotności 0,05 od odmian w siewie czystym i charakteryzowały się najwyższą stabilnością.

Współczynniki zmienności dla mieszanek dwuskładnikowych wynosiły od 3,92 do 4,83\%, nieco niższe były współczynniki zmienności dla mieszanek trzyskładnikowych i wynosiły od 3,50 do 3,83\%.

W świetle uzyskanych wyników i ich analizy można stwierdzić, że mieszanki dwuskładnikowe i trzyskładnikowe były bardziej stabilne w plonowaniu niż odmiany w siewie czystym, przy czym mieszanki trzyskładnikowe były najbardziej stabilne (tab. 3).

$\mathrm{Na}$ podstawie analizy plonów rzeczywistych i oczekiwanych oceniono wpływ poszczególnych odmian w tworzeniu plonu mieszanek. Dla przykładu, do oceny wpływu odmian w mieszance Basza + Blask wpisano po 0,01 dt/ha, ponieważ jest to różnica między plonami oczekiwanymi i rzeczywistymi, jak wynika $\mathrm{z}$ tabeli 2 .

Takie postępowanie realizowano dla mieszanek dwuskładnikowych i trzyskładnikowych, eliminując po jednym składniku, co pozwoliło oszacować plonowanie poszczególnych odmian w zasiewach mieszankowych (tab. 4). Uzyskane wyniki pozwoliły stwierdzić, że największą przydatność do uzyskania wysokich plonów w mieszankach miała odmiana Rubinek i Antek. Odmiana Rubinek plonowała w siewie czystym wysoko, a w mieszankach następował jeszcze wzrost plonu. Odmiana Antek plonowała w siewie czystym istotnie niżej od odmiany Rubinek, natomiast w mieszankach następował znaczny wzrost plonu.

Najważniejszą zaletą uprawy zbóż w mieszankach jest zwiększenie bioróżnorodności, która z kolei umożliwia, dzięki odrębności odmian/gatunków komponentów 
Tabela 1. Analiza wariancji i średnie kwadraty

Table 1. Variance analysis and mean squares

\begin{tabular}{l|c|c|c}
\hline \multicolumn{1}{c|}{$\begin{array}{c}\text { Źródło zmienności } \\
\text { Source of variation }\end{array}$} & $\begin{array}{c}\text { Liczba stopni swobody } \\
\text { Degrees of freedom }\end{array}$ & $\begin{array}{c}\text { Sumy kwadratów } \\
\text { Sum of squares }\end{array}$ & $\begin{array}{c}\text { Średni kwadrat } \\
\text { Mean squares }\end{array}$ \\
\hline Całkowita - Total & ek-1 - 199 & 15105,4882 & $1805,9906^{* *}$ \\
\hline Środowiska - Enviroment (E) & $\mathrm{e}-1-7$ & 12641,9343 & $45,6366^{* *}$ \\
\hline Obiekty - Object $(\mathrm{G})$ & $\mathrm{k}-1-24$ & 1095,2788 & $8,1445^{* *}$ \\
\hline Interakcja - Interaction $(\mathrm{G} \times \mathrm{E})$ & $(\mathrm{e}-1)(\mathrm{k}-1)-168$ & 1368,2751 & 0,7456 \\
\hline Błąd- Error & $\mathrm{n}(\mathrm{k}-1)(\mathrm{n}-1)-576$ & 429,4766 & \\
\hline
\end{tabular}

Tabela 2. Plony rzeczywiste (r) i oczekiwane (o) oraz współczynniki zmienności dla odmian i mieszanek jęczmienia jarego w Bąkowie i Kościelnej Wsi w latach 2010-2013

Table 2. Actual (r) and expected (o) yields and coefficients of variation for spring barley varieties and mixtures at Bąków and Kościelna Wieś in 2011-2013

\begin{tabular}{|c|c|c|c|c|}
\hline $\begin{array}{l}\text { Odmiana/mieszanka } \\
\text { Varieties/mixtures }\end{array}$ & $\begin{array}{c}\text { Plon rzeczywisty } \\
\text { Actual yield } \\
(\mathrm{r}) \\
{[\mathrm{dt} / \mathrm{ha}]}\end{array}$ & $\begin{array}{c}\text { Plon oczekiwany } \\
\text { Expected yield } \\
\text { (o) } \\
{[\mathrm{dt} / \mathrm{ha}]}\end{array}$ & $\begin{array}{c}\text { Różnica } \\
\text { Difference } \\
\text { (r-o) } \\
{[\mathrm{dt} / \mathrm{ha}]}\end{array}$ & $\begin{array}{c}\text { Współczynnik zmienności } \\
\text { Coefficient of variation } \\
\text { (CV\%) }\end{array}$ \\
\hline Basza & 53,84 & - & - & 8,81 \\
\hline Blask & 54,66 & - & - & 6,71 \\
\hline Antek & 45,91 & - & - & 10,48 \\
\hline Skarb & 56,73 & - & - & 6,13 \\
\hline Rubinek & 55,18 & - & - & 5,94 \\
\hline $\begin{array}{l}\text { Średni plon odmian w siewie czystym } \\
\text { Average yield for varieties in pure stands }\end{array}$ & 53,26 & - & - & - \\
\hline Basza/Blask & 54,26 & 54,26 & $+0,01$ & 4,97 \\
\hline Antek/Basza & 52,35 & 49,88 & $+2,47$ & 5,77 \\
\hline Basza/Skarb & 57,26 & 55,28 & $+1,98$ & 5,29 \\
\hline Basza/Rubinek & 58,42 & 54,51 & $+3,91$ & 3,32 \\
\hline Antek/Blask & 50,72 & 50,29 & $+0,43$ & 5,82 \\
\hline Antek/Skarb & 54,29 & 51,32 & $+2,97$ & 3,42 \\
\hline Antek/Rubinek & 53,45 & 50,55 & $+2,90$ & 4,36 \\
\hline Blask/Skarb & 58,24 & 55,70 & $+2,54$ & 2,34 \\
\hline Blask/Rubinek & 57,96 & 54,92 & $+3,04$ & 2,53 \\
\hline Rubinek/Skarb & 56,77 & 55,96 & $+0,81$ & 6,41 \\
\hline $\begin{array}{l}\text { Średni plon mieszanek dwuskładnikowych } \\
\text { Average yield for two-way mixtures }\end{array}$ & 55,37 & - & - & - \\
\hline Suma różnic - Sum of differences & - & - & 21,06 & - \\
\hline Antek/Basza/Blask & 53,17 & 51,47 & $+1,70$ & 3,94 \\
\hline Antek/Blask/Skarb & 54,43 & 52,43 & $+2,00$ & 3,50 \\
\hline Antek/Basza/Rubinek & 54,39 & 51,64 & $+2,75$ & 4,69 \\
\hline Antek/Blask/Rubinek & 54,21 & 51,92 & $+2,29$ & 2,84 \\
\hline Antek/Basza/Skarb & 54,86 & 52,16 & $+2,70$ & 2,58 \\
\hline Blask/Rubinek/Skarb & 57,16 & 55,52 & $+1,64$ & 4,02 \\
\hline Basza/Blask/Rubinek & 57,07 & 54,56 & $+2,51$ & 2,60 \\
\hline Antek/Rubinek/Skarb & 56,13 & 52,61 & $+3,52$ & 3,48 \\
\hline Basza/Blask/Skarb & 57,24 & 55,08 & $+2,16$ & 4,46 \\
\hline Basza/Rubinek/Skarb & 56,68 & 55,25 & $+1,43$ & 4,74 \\
\hline $\begin{array}{l}\text { Średni plon mieszanek trzyskładnikowych } \\
\text { Average yield for three-way mixtures }\end{array}$ & 55,53 & - & - & - \\
\hline Suma różnic - Sum of differences & - & - & 22,70 & - \\
\hline
\end{tabular}

\footnotetext{
Średnia ogólna - Overall average - 55,01 q/ha; NIR (0,05) - LSD (0.05) - 4,6044; NIR (0,01) - LSD (0.01) - 6,0794; NIRP - 8,37
} 
Tabela 3. Współczynniki zmienności (CV\%) plonowania odmian jęczmienia jarego w siewie czystym i mieszankach

Table 3. Coefficients of variation $(\mathrm{CV} \%)$ of spring barley varieties and mixtures yielding

\begin{tabular}{|c|c|c|c|c|}
\hline \multirow{2}{*}{$\begin{array}{l}\text { Odmiany } \\
\text { Varieties }\end{array}$} & \multirow{2}{*}{$\begin{array}{l}\text { Plon ziarna } \\
\text { Grain yield } \\
\text { [dt/ha] }\end{array}$} & \multicolumn{3}{|c|}{$\begin{array}{l}\text { Współczynniki zmienności plonowania } \\
\text { Yielding coefficients of variation } \\
(\mathrm{CV} \%)\end{array}$} \\
\hline & & $\begin{array}{l}\text { odmiany w siewie czystym } \\
\text { varieties in pure stands }\end{array}$ & $\begin{array}{l}\text { mieszanki trzyskładnikowe } \\
\text { three-way mixtures }\end{array}$ & $\begin{array}{l}\text { mieszanki dwuskładnikowe } \\
\text { two-way mixtures }\end{array}$ \\
\hline Basza & 56,02 & 8,81 & 3,83 & 4,83 \\
\hline Blask & 55,72 & 6,71 & 3,56 & 3,92 \\
\hline Antek & 48,20 & 10,50 & 3,50 & 4,84 \\
\hline Skarb & 57,59 & 6,13 & 3,80 & 4,37 \\
\hline Rubinek & 55,84 & 5,94 & 3,73 & 4,15 \\
\hline
\end{tabular}

Tabela 4. Przydatność odmian jęczmienia jarego do uprawy w mieszankach na podstawie plonowania w Bąkowie i Kościelnej Wsi w latach 2010-2013

Table 4. Suitability of spring barley varieties to compose mixtures on the base of yielding at Bąków and Kościelna Wieś in 2011-2013

\begin{tabular}{|c|c|c|c|c|c|}
\hline \multirow[t]{2}{*}{$\begin{array}{l}\text { Mieszanka } \\
\text { Mixtures }\end{array}$} & \multicolumn{5}{|c|}{$\begin{array}{c}\text { Różnice między plonami rzeczywistymi (r) } \\
\text { i oczekiwanymi (o) dla odmian }\end{array}$} \\
\hline & Basza & Blask & Antek & Skarb & Rubinek \\
\hline Basza/Blask & $+0,01$ & $+0,01$ & - & - & - \\
\hline Basza/Antek & $+2,47$ & - & $+2,47$ & - & - \\
\hline Basza/Skarb & $+1,98$ & - & - & $+1,98$ & - \\
\hline Basza/Rubinek & $+3,91$ & - & - & - & $+3,91$ \\
\hline Antek/Blask & - & $+0,43$ & $+0,43$ & - & - \\
\hline Antek/Skarb & - & - & $+2,97$ & $+2,97$ & - \\
\hline Antek/Rubinek & - & - & $+2,90$ & - & $+2,90$ \\
\hline Blask/Skarb & - & $+2,54$ & - & $+2,54$ & - \\
\hline Blask/Rubinek & - & $+3,04$ & - & - & $+3,04$ \\
\hline Rubinek/Skarb & - & - & - & $+0,81$ & $+0,81$ \\
\hline $\begin{array}{l}\text { Suma dla dwuskładnikowych mieszanek } \\
\text { Sum for two-way mixtures }\end{array}$ & $+8,37$ & $+6,02$ & $+8,77$ & $+8,30$ & $+10,66$ \\
\hline Antek/Basza/Blask & $+1,70$ & $+1,70$ & $+1,70$ & - & - \\
\hline Antek/Blask/Skarb & - & $+2,00$ & $+2,00$ & $+2,00$ & - \\
\hline Antek/Basza/Rubinek & $+2,75$ & - & $+2,75$ & - & $+2,75$ \\
\hline Antek/Blask/Rubinek & - & $+2,29$ & $+2,29$ & - & $+2,29$ \\
\hline Antek/Basza/Skarb & $+2,70$ & - & $+2,70$ & $+2,70$ & - \\
\hline Blask/Rubinek/Skarb & - & $+1,64$ & - & $+1,64$ & $+1,64$ \\
\hline Blask/Basza/Rubinek & $+2,51$ & $+2,51$ & - & - & $+2,51$ \\
\hline Antek/Rubinek/Skarb & - & - & $+3,52$ & $+3,52$ & $+3,52$ \\
\hline Basza/Blask/Skarb & $+2,16$ & $+2,16$ & - & $+2,16$ & - \\
\hline Basza/Rubinek/Skarb & $+1,43$ & - & - & $+1,43$ & $+1,43$ \\
\hline $\begin{array}{l}\text { Suma dla trzyskładnikowych mieszanek } \\
\text { Sum for three-way mixtures }\end{array}$ & $+13,25$ & $+12,30$ & $+14,96$ & $+13,45$ & $+14,14$ \\
\hline $\begin{array}{l}\text { Suma dla dwuskładnikowych } \\
\text { i trzyskładnikowych mieszanek } \\
\text { Sum for two- and three-way mixtures }\end{array}$ & $+21,62$ & $+18,32$ & $+23,73$ & $+21,75$ & $+24,80$ \\
\hline
\end{tabular}

mieszanki, lepsze wykorzystanie zasobów środowiska. Dobór odmian do mieszanek nie może być jednak przypadkowy, ponieważ reakcja roślin na sąsiadujące rośliny jest pozytywna lub niekorzystna, więc kompo- nowanie składu mieszanek muszą poprzedzać doświadczenia polowe, jak również szczegółowe badania epidemiologiczno-genetyczne. Wiele doniesień naukowych zwraca uwagę na fakt, że mieszanki dzięki zróżnicowaniu 
genetycznemu, sa bardziej tolerancyjne na gorsze warunki siedliskowe i agrotechniczne w porównaniu do siewów czystych (Wolfe i wsp. 1997; Finckh i wsp. 2000; Gacek 2000; Tratwal i Gacek 2010; Nadziak i Tratwal 2012). $\mathrm{W}$ obrębie łanu, warunki, które są niesprzyjające $\mathrm{z}$ różnych względów dla jednego z komponentów mogą być wykorzystane przez drugi składnik mieszanki. Objawia się to nie zawsze istotnym wzrostem plonowania, ale co ważniejsze, jego większą stabilnością. W świetle uzyskanych wyników można stwierdzić, że zasiewy mieszane mogą być polecane do uprawy w każdym systemie produkcji rolniczej, a w szczególności w rolnictwie zrównoważonym i ekologicznym, zwłaszcza w kontekście wytycznych do jakich zobowiązują zapisy w Dyrektywie Parlamentu Europejskiego i Rady 2009/128/WE ustanawiającej ramy wspólnotowego działania na rzecz zrównoważonego stosowania pestycydów (Dyrektywa 2009). Mogą być również przydatne w tworzeniu, a następnie wdrażaniu do praktyki rolniczej integrowanych programów ochrony zbóż przez wykorzystanie zasiewów mieszanych jako proekologicznej metody poprawy plonowania.

\section{Wnioski / Conclusions}

1. Przeprowadzone analizy plonowania odmian jęczmienia jarego w zasiewach mieszanych wskazały odmiany do komponowania tych zasiewów.

2. Odmiany jęczmienia jarego Rubinek i Antek wykazały się najlepszą przydatnością do komponowania zasiewów mieszanych przyczyniając się do największej zwyżki plonowania.

3. Istotnie najniżej plonująca odmiana jęczmienia jarego Antek w siewie czystym dawała porównywalnie istotnie wyższe plony w zasiewach mieszanych.

4. Mieszanki międzyodmianowe jęczmienia jarego, zwłaszcza mieszanki trzyskładnikowe, były bardziej stabilne w plonowaniu niż odmiany w siewie czystym.

\section{Literatura / References}

Allard R.W., Adams J. 1969. Population studies in predominantly self-pollinating species. XIII. Intergenotypic competition and population structure in barley and wheat. The American Naturalist 103: 620-645.

Dyrektywa Parlamentu Europejskiego i Rady 2009/128/WE z dnia 21.10.2009 r. ustanawiająca ramy wspólnotowego działania na rzecz zrównoważonego stosowania pestycydów (Dz. Urz. UE L 309/71 z dnia 24.11.2009 r.).

Finckh M.R., Gacek E.S., Goyeau H., Lannou Ch., Merz U., Mundt C.C., Munk L., Nadziak J., Newton A.C., de Vallavieille-Poppe C., Wolfe M.S. 2000. Cereal variety and species mixtures in practice, with emphasis on disease resistance. Agronomie 20: 813-837.

Gacek E. 2000. Wykorzystanie różnorodności genetycznej roślin w zwalczaniu chorób roślin uprawnych. [Utilization of genetical diversity to control the diseases of cultivated plants]. Postępy Nauk Rolniczych 5: 17-25.

Gacek E., Czembor H.J., Nadziak J. 1996. Wpływ zróżnicowania genetycznego w mieszaninach i mieszankach zbożowych na rozwój chorób i plonowanie. Biuletyn Instytutu Hodowli i Aklimatyzacji Roślin 200: 203-209.

Gacek E., Czembor H.J., Nadziak J. 1997. Zastosowanie mieszanin odmian do poprawy zdrowotności oraz wysokości plonowania pszenicy ozimej. [The use of cultivar mixtures for improving disease resistance and yield in winter wheat]. Biuletyn Instytutu Hodowli i Aklimatyzacji Roślin 201: 81-83.

Knott E.A., Mundt C.C. 1990. Mixing ability analysis of wheat cultivar mixture under diseased and non-diseased conditions. Theoretical and Applied Genetics 80: 313-320.

Nadziak J., Tratwal A. 2012. Określenie przydatności odmian do uprawy w zasiewach mieszanych pszenicy ozimej. [Usefulness of winter wheat varieties for mixtures]. Biuletyn Instytutu Hodowli i Aklimatyzacji Roślin 264: 49-54.

Noworolnik K. 2000. Mieszanki zbożowo-strączkowe w systemie rolnictwa zrównoważonego. Pamiętnik Puławski 120 (2): 325-329.

Michalski T., Kowalik I., Idziak R., Horoszkiewicz-Janka J. 2004. Mieszanki jako ekologiczna metoda uprawy zbóż. Wybrane zagadnienia ekologiczne we współczesnym rolnictwie. Monografia. Państwowy Instytut Maszyn Rolniczych, Poznań: 28-36.

Szempliński W., Budzyński W. 2011. Cereal mixtures in polish scientific literature in the period 2003-2007. Review article. Acta Scientiarum Polonorum, Agricultura 10 (2): 127-140.

Tratwal A., Gacek E. 2010. Znaczenie odmian odpornych na choroby i systemów różnicowania uprawy w integrowanej ochronie jęczmienia ozimego i jarego. s. 30-34. W: „Integrowana produkcja jęczmienia jarego” (M. Korbas, M. Mrówczyński, red.). Instytut Ochrony Roślin - Państwowy Instytut Badawczy, Poznań, 140 ss.

Tratwal A., Law J., Philpott H., Horwell A., Garner J. 2007a. The possibilities of reduction of winter barley chemical protection by growing variety mixtures. Part I. Effect on powdery mildew level. Journal of Plant Protection Research 47 (1): 65-77.

Tratwal A., Law J., Philpott H., Horwell A., Garner J. 2007b. The possibilities of reduction of winter barley chemical protection by growing variety mixtures. Part II. Effect on yield. Journal of Plant Protection Research 47 (1): 79-86.

Tratwal A., Walczak F. 2010. Powdery mildew (Blumeria graminis) and pest occurrence reduction in spring cereals mixtures. Journal of Plant Protection Research 50 (3): 372-377.

Trenbath B.R. 1974. Biomass productivity of mixtures. Advances in Agronomy 26: 171-210.

Węgrzyn S. 1989. Wyznaczanie wartości cech mierzalnych w warunkach interakcji genotypowo-środowiskowej. [Estimation of measurable traits under conditions of the genotype-environment interaction]. Zeszyty Problemowe Postępów Nauk Rolniczych 198 (382): 50-60.

Wolfe M.S. 1990. Intra-crop diversification: disease, yield and quality. Monograph. British Crop Protection Council 45: $105-114$.

Wolfe M.S., Lannou C., Pope C., Finckh M.R., Munk L., Merz U., Valenghi D., Gacek E. 1997. Variety mixtures in theory and practice. Cost Action 817. Compiled by Working Group 2. INRA-Grignon-France, May 1997, 15 pp. 